\title{
Numerical simulation of the vertical migration of Microcystis (cyanobacteria) colonies based on turbulence drag
}

\author{
Hongru ZHAO, ${ }^{1}$ Wei ZHU, ${ }^{1,2 *}$ Huaimin CHEN, ${ }^{1}$ Xiaohua ZHOU,${ }^{1}$ Ruochen WANG, ${ }^{1}$ Ming LI ${ }^{3}$ \\ ${ }^{1}$ College of Environment, Hohai University, 210098 Nanjing; ${ }^{2}$ National Engineering Research Center of Water Resources Efficient Uti- \\ lization and Engineering Safety, 210098 Nanjing; ${ }^{3}$ College of Resources and Environment, Northwest A\&F University, 712100 Yangling, \\ China \\ *Corresponding author: zhuweiteam.hhu@gmail.com
}

\begin{abstract}
The vertical migration and accumulation of Microcystis is an important process in water blooms, and colony migration is influenced by colony size and wind-wave disturbance. The vertical migration of Microcystis colonies in turbulence can be simulated in a numerical model. In this study, we model such migration by coupling the colony size and hydrodynamics, including the gravity, colony buoyancy, and the viscous drag force of turbulence. The turbulence intensity was represented by the turbulent kinetic energy $\left(\mathrm{K}_{\mathrm{Z}}\right)$; the larger the $\mathrm{K}_{\mathrm{Z}}$, the stronger the wind-wave disturbance. The simulated vertical distribution of Microcystis well agreed with the measured values in a laboratory experiment indicating that our model can simulate the vertical distribution of Microcystis under different hydrodynamic conditions. We also found a size-dependent critical turbulent kinetic energy $\left(\mathrm{TK}_{\mathrm{Z}}\right)$, such that if the turbulent kinetic energy of water exceeds the critical value (i.e., $\mathrm{K}_{\mathrm{Z}}>T \mathrm{~K}_{\mathrm{Z}}$ ), the colonies sink under the drag forces of turbulence; conversely, if $\mathrm{K}_{\mathrm{Z}}<\mathrm{TK}_{\mathrm{Z}}$, the colonies can overcome the turbulent mixing and float. The $T \mathrm{~K}_{\mathrm{Z}}$ of each colony was linearly related to colony diameter. The model is crucial for prediction and prevention of water blooms. The simulated threshold turbulent kinetic energy, at which water blooms disappear in Lake Taihu (a large freshwater lake in the Yangtze Delta, Jiangsu Province, China), was $55.5 \mathrm{~cm}^{2} \mathrm{~s}^{-2}$.
\end{abstract}

Key words: Viscous drag force of turbulence; colony size; turbulent kinetic energy; vertical migration; $T \mathrm{~K}_{\mathrm{Z}}$.

Received: May 2016. Accepted: October 2016.

\section{INTRODUCTION}

Cyanobacterial blooms are a major environmental problem in eutrophic lakes and Microcystis is the most common genus of bloom forming cyanobacterium. Water blooms can be effectively predicted in numerical models that simulate the occurrence and disappearance of water blooms. The cyclic appearance and disappearance of water blooms is mainly driven by the spatial aggregation and dispersion of Microcystis by wind waves (Wu and Kong, 2009; Zhu et al., 2014). Consequently, this process is assumed in numerical simulations of blooms.

Microcystis colonies achieved vertical migration with the help of buoyancy regulating system of gas vesicles and ballast (e.g., carbohydrate) (Oliver and Walsby, 1984; Kromkamp et al., 1984). These mechanisms were well described by Walsby (1994) that Microcystis colonies always rise during night due to synthesis of gas vesicles and carbohydrate utilization. In the contrary, they sink in the day because of the accumulation of carbohydrate and collapse of gas vesicles. In a laboratory study, Nakamura et al. (1993) found that the measured floating velocity of $M i-$ crocystis is proportional to colony size. Wu and Kong (2009) investigated Microcystis blooms in Lake Taihu, a large freshwater lake in the Yangtze Delta of Jiangsu Province, China. They found that large Microcystis colonies $(>120 \mu \mathrm{m})$ can overcome wind-wave disturbance and thus accumulate at the water surface, whereas small colonies $(<36 \mu \mathrm{m})$ tend to mix with the turbulence. Chien et al. (2013) simulated the vertical migration of differently sized colonies in a trajectory model, and reported that large colonies $(\geq 300 \mu \mathrm{m})$ can resist turbulent mixing and undertake diurnal vertical migration, whereas smaller colonies are more homogenously scattered in the vertical direction. According to Stokes' law $\left(V=2 g r^{2}(\rho-) A /(9 \Phi n)\right.$, where $V$ and $r$ are the velocity and radius of the colony, respectively, $\rho$ and $\rho_{w}$ are the densities of the colony and water, respectively, $A$ is the proportion of cell volume relative to colony volume, $\Phi$ the form resistance and $n$ the viscosity of the water), without any other interference, the vertical migration velocity of Microcystis colonies mainly depends on the cell density and the colony size (Reynolds et al., 1987), and the floating rate is proportional to the square of the colony diameter. All of these studies suggest that colony size directly affects the vertical migration of Microcystis.

Besides the internal factors, the vertical distribution of Microcystis is mainly driven by wind-wave distur- 
bance. George and Edwards (1976) investigated the relationship between water blooms and wind speed in Lake Nynyod (South Wales), and found that algae gather into blooms at the water surface at wind speeds below $3.0 \mathrm{~ms}^{-}$ ${ }^{1}$, but disperse at wind speeds of $3.0 \mathrm{~ms}^{-1}$. Cao et al. (2006) conducted a field investigation of Lake Taihu, and observed that at a wind speed of $2.0 \mathrm{~m} \mathrm{~s}^{-1}$ and wave height of $4.4 \mathrm{~cm}$, approximately $37 \%$ of the whole Microcystis biomass gathers on the water surface, forming water blooms. Conversely, at a wind speed of $3.1 \mathrm{~ms}^{-1}$ and wave height of $6.2 \mathrm{~cm}$, the Microcystis tend to distribute homogenously through the water column. Wu et al. (2013) found that disturbances mix the Microcystis in deeper layers. In a field study, Ding et al. (2012) investigated the effect of the tropical storm Morakot on Lake Taihu's water blooms, and observed that chlorophyll a concentration homogenously distributed during the typhoon crossing, and water blooms reappeared on the surface after the typhoon. The above studies show that turbulent mixing determines the vertical distribution of Microcystis. However, although these studies relate wind speed to water blooms, they do not clarify the motion mechanism of Microcystis under different hydrodynamic conditions, nor the effect of turbulence on the migration of colonies.

Many researchers have established mathematical models to study the vertical migration and distribution of Microcystis colonies under different hydrodynamic conditions (Visser et al., 1997; Wallace et al., 2000; Huisman and Sommeijer, 2002; Rabouille et al., 2005; Serizawa et al., 2008; Chen et al., 2009). Visser et al. (1997) combined a model of cell density change with Stokes' law, and simulated the vertical migration of Microcystis colonies in static water. Wallace et al. (2000) combined a buoyancy regulation model with a hydrodynamic model into a vertical migration model of Microcystis, and computed the vertical position of Microcystis in a turbulent shallow lake (depth $1.4 \mathrm{~m}$ ). A similar vertical migration model of $\mathrm{Mi}$ crocystis colonies was developed by Chen et al. (2009). The fluid mechanics described particle migration in the flow in details and indicated that the viscous drag force was the driven factor making the particles to migrate in the flow (White et al., 1977; Van Rijn, 1984). This principle could also be applied to Microcystis colonies. The viscous drag was ignored in the models of the vertical migration of Microcystis colony. To more accurately simulate the vertical migration of Microcystis colonies, we require numerical models based on the most influential physical processes.

In this study, we investigate the effect of Microcystis colony size on resistance to disturbance. To this end, we develop a mathematical model that allows floating and sinking of Microcystis colonies under viscous drag as well as gravity and buoyancy. The mathematical model is verified in a laboratory experiment.

\section{METHODS}

\section{Forces acting on Microcystis colonies}

In the present model, the forces acting on Microcystis colonies are restricted to the vertical direction. The three main forces acting on Microcystis in water (where the $z$ axis is positive downward) are listed below.

1) Gravity

$$
G=m g=\rho_{s} g V
$$

2) Buoyancy

$$
F_{f}=\rho_{w} g V_{f}
$$

3) Viscous drag force of turbulence

$$
F_{D}=\frac{C_{D} \rho_{w} \pi D^{2}\left(u_{w}-v_{S}\right)\left|u_{w}-v_{S}\right|}{8}
$$

These forces are summed to give the resultant force

$$
\begin{aligned}
& F_{h}=\frac{C_{D} \rho_{w} \pi D^{2}\left(u_{w}-v_{S}\right)\left|u_{w}-v_{S}\right|}{8}- \\
& \left(\rho_{w}-\rho_{S}\right) g V=m a=m \frac{d v_{S}}{d t}
\end{aligned}
$$

$\rho_{w}$ and $\rho_{s}$ as the densities of water $\left(998 \mathrm{~kg} \mathrm{~m}^{-3}\right)$ and $M i-$ crocystis, respectively. Reynolds et al. (1981) indicated that the lowest density of Microcystis colonies in Bleham Tarn, Cumbria was $985 \mathrm{~kg} \mathrm{~m}^{-3}$. In addition, we recently measured the density of Microcystis colonies taken from Lake Taihu and found that the average value was $985 \mathrm{~kg}$ $\mathrm{m}^{-3}$. Therefore, we set $\rho_{s}$ as $985 \mathrm{~kg} \mathrm{~m}^{-3}$ in the current study. We also require the gravitational acceleration $g(9.8$ $\mathrm{m} \mathrm{s}^{-2}$ ), the volumes $V$ of a single colony and $V_{f}$ of the colony in water, the colony diameter $D$, and the drag coefficient $C_{D}$. As the colony is assumed to be spherical, its volume is given by $V=\pi D^{3} / 6$; further, we assume $V_{f}=V$, and set $C_{D}$ to 0.45 in turbulence (Dong et al., 2007). We also define $u_{w}$ and $v_{s}$ as the vertical velocities of flow and vertical migration of Microcystis colonies respectively, and $a$ as the acceleration of the colonies. The mass $m$ of a single colony is calculated as $m=\rho_{s} V$.

\section{Vertical position of Microcystis colonies}

As turbulence varies in a transient manner, we divided the motion time $t$ into $n$ equal segments with a time step $t$ of $10^{-4} \mathrm{~s}$. After discretizing eq. (4) as eq. (5), we solved the vertical migration velocity of each Microcystis colony 
by a finite difference scheme implemented in MATLAB R2009a software (The MathWorks).

$$
\begin{aligned}
& F_{h}=\frac{C_{D} \rho_{w} \pi D^{2}\left(u_{w i}-v_{s i}\right)\left|u_{w i}-v_{s i}\right|}{8}- \\
& \left.\rho_{S}\right) g V=m \frac{v_{s i+1}-v_{s i}}{t}
\end{aligned}
$$

The initial vertical migration velocity of the colonies (regardless of their diameter) was set to $0 \mathrm{~m} \mathrm{~s}^{-1}\left(v_{s 0}=0\right)$. $v_{s i}$ was determined from the known vertical velocities of flow $\left(u_{w i-1}\right)$. Within the very short time step, the motion of the colonies is assumed uniform and their instantaneous displacement is given by $S_{i}=v_{s i} \times t$. The total displacement $(S)$ and position $(z)$ of a Microcystis colony in water are described by the following flow equations:

$$
S=S_{1}+S_{2}+\ldots+S_{n}
$$

$z=z_{0}+S$

Where $z_{0}$ is the initial position of the Microcystis colony.

\section{Turbulent kinetic energy}

In this study, the disturbance intensity was represented by the turbulent kinetic energy $\left(K_{Z}\right)$, which is calculated by eq. (8):

$K_{Z}=\frac{1}{2 n}\left[\left(u_{1}-\bar{u}\right)^{2}+\left(u_{2}-\bar{u}\right)^{2}+\ldots+\left(u_{n}-\bar{u}\right)^{2}\right]$
Here, $u_{i}$ are the instantaneous vertical flow velocities, and $\bar{u}$ is their mean value, $n$ is the number of $u_{i}$. The larger the $K_{Z}$, the stronger the disturbance.

\section{Laboratory experiment (vertical wave-making simulator) and simulation}

The effects of disturbance on the vertical migration and distribution of Microcystis colonies were investigated in a vertical wave-making simulator. Survival kinds of amplitude $A(4,6,8 \mathrm{~cm})$ with variable frequency $(1 / T)$ were set to obtain different hydrodynamic conditions. $M i-$ crocystis samples taken from Lake Taihu, which were mainly composed of $M$. aeruginosa, were used in this experiment (Xiao et al., 2013).

\section{Measurement of vertical flow velocity}

The vertical flow velocity $(u)$ in the simulator was measured by Particle Image Velocimetry (PIV), and the $K_{Z}$ was calculated by Eq. (8). Fig. 1a shows the working principle of PIV. Before measurement, the tracing particles are placed in the simulator with high flow, and one side of the simulator is illuminated by a pair of lasers. The trajectories of the particles are then tracked perpendicularly to the laser beam by a high-speed CCD camera. The particle trajectories are photographed over $100 \mu$ s (the time step of the lasers), and the two-dimensional velocity of the water particle is calculated. Because the laser beam must pass through regions containing liquid, the lowest water level must lie outside the light irradiation area. To ensure this condition, we placed the laser at $50 \mathrm{~cm}$ and 80 $\mathrm{cm}$ from the bottom of the simulator (Fig. 1b). The verti-

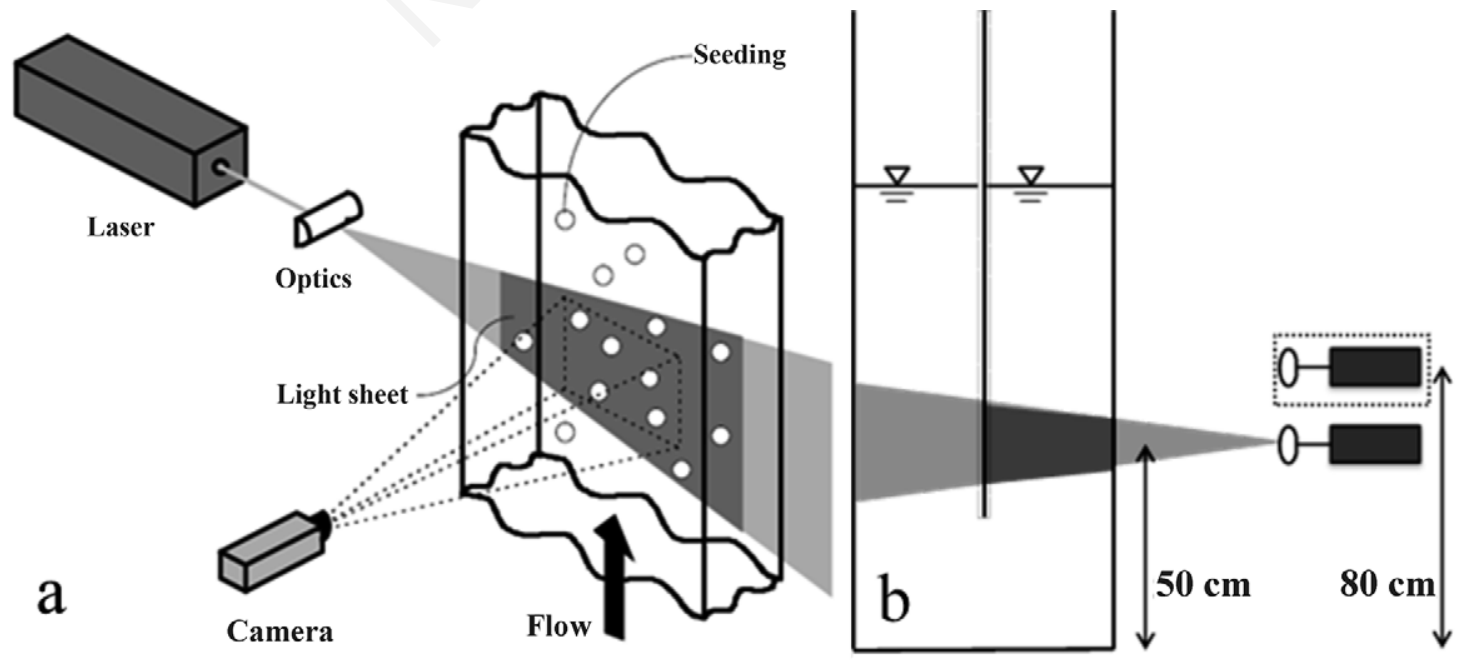

Fig. 1 a) The working principle of PIV. b) Area of flow measurement. 
cal flow velocities were calculated from 80 photographs under different hydrodynamic conditions.

\section{Simulation of vertical flow velocity}

Considering the wave patterns in the simulator and random turbulence, the vertical flow velocity in the simulator was estimated by Eq. (9), where $A, T$ are amplitude and period set in experiment, respectively, $w=2 \pi / T$. A random number $R$ was employed here to indicate random fluctuation component of turbulence which was always described as $u=\bar{u}+u$ ' (where $u$ is the instantaneous velocity, $\bar{u}$ is the average velocity, and $u$ ' is the random fluctuation component).

$u_{w}=A w \sin (w t)+A R / T$

The vertical flow of the wave-making simulator under different conditions was simulated by eq. (9). For each hydrodynamic condition, the flow velocities were calculated in one period, and the turbulent kinetic energy $\left(K_{Z}\right)$ was estimated by eq. (8).

\section{Simulation of vertical distribution of Microcystis}

Four groups of Microcystis colonies (un-sieved original mixed-size Microcystis samples, colony sizes of 100$300,300-500$ and $>500 \mu \mathrm{m}$ ) were operated in the experiment of vertical distribution of Microcystis under different hydrodynamic conditions (Xiao et al., 2013).

Simulation was conducted in following steps. All $\mathrm{Mi}$ crocystis colonies were initially set at the surface $(z \mathrm{O}=0)$. And colonies' displacements at different time (1, 5, $10 \mathrm{~min})$ were calculated by applying eq. (1) - eq. (7). Then, colonies at a particular depth $(z)$ were counted $\left(N_{z}\right)$ according to their displacements. Finally, the Chlorophyll a concentration at different depths was determined through multiplying ratio of $N z$ and $N$ (the total number of the colonies in the system) by the whole Chlorophyll a concentration $C_{0}$ (acquired from laboratory experiment). Thus, the Microcystis concentration at depth $(z)$ is given by eq. (10):

$$
C_{z}=C_{0} N_{Z} / N
$$

The measured results obtained by Xiao et al. (2013) was used to assess the consistency of the predicted results and the measured results.

\section{Critical hydrodynamic conditions}

The condition under which the colonies happen to sink is the critical hydrodynamic disturbance, below this hydrodynamic condition, the Microcystis colonies can resist the water motions and float up. In this study, the critical turbulent kinetic energy $\left(\mathrm{T} K_{Z}\right)$ was used to represent the disturbance intensity. If the turbulent kinetic energy of the water body exceeds the critical kinetic energy of the colonies (i.e., $K_{Z}>\mathrm{T} K_{Z}$ ), the colonies will sink under the drag forces of turbulence. Conversely, if the turbulent kinetic energy of water is below the critical kinetic energy of the colonies $\left(K_{Z}<\mathrm{T} K_{Z}\right)$, the colonies will float.

Individual colony was placed on the water surface separately. The critical turbulent kinetic energy $\left(\mathrm{T} K_{Z}\right)$ under varying hydrodynamic conditions was obtained when the colony happened to leave the water surface. The experiments were performed in three times.

In the numerical simulation, the colony displacements were investigated under increasing hydrodynamic disturbances until the displacement is just greater than zero. The critical hydrodynamic conditions of colonies with different diameters $(100,200,300,400,500 \mu \mathrm{m})$ were obtained, hence their critical turbulent kinetic energies $\left(\mathrm{T} K_{Z}\right)$. Linear regression was used to estimate the dependence of critical kinetic energy on colony size.

\section{RESULTS}

\section{Turbulent kinetic energy under different hydrodynamic conditions}

The simulated turbulent kinetic energy $\left(K_{Z}\right)$ under different hydrodynamic conditions is showed in Tab. 1 and Fig. 2. The turbulent kinetic energy $\left(K_{Z}\right)$ is a quadratic function of the hydrodynamic conditions $(A / T)$ as equation 11. The measured and simulated values favorably agree, confirming that our model can simulate the flows in a vertical wave-making simulator.

$K_{Z}=10.034(A / T)^{2}$

\section{Vertical distribution of Microcystis}

After estimating the displacements of all Microcystis colonies under various experimental conditions, we calculated the chlorophyll a concentrations at different depths by

Tab. 1. The simulated turbulent kinetic energy in different hydrodynamic conditions.

\begin{tabular}{lccccccc}
\hline Amplitude $A /$ period $\mathrm{T}\left(\mathrm{cm} \mathrm{s}^{-1}\right)$ & $8 / 2$ & $6 / 2$ & $8 / 3$ & $6 / 3$ & $6 / 4$ & $5 / 4$ & $4 / 4$ \\
\hline Hydrodynamic condition $A / T\left(\mathrm{~cm} \mathrm{~s}^{-1}\right)$ & 4 & 3 & 2.67 & 2 & 1.5 & 1.25 & 1 \\
\hline Turbulent kinetic energy $K_{Z}\left(\mathrm{~cm}^{2} \mathrm{~s}^{-2}\right)$ & 160 & 90 & 71 & 40 & 23 & 16 & 10 \\
\hline
\end{tabular}


eq. (10), and compared them with the experimental results. Fig. 3 showed the variation in vertical distribution of $\mathrm{Mi}$ crocystis colonies $(300-500 \mu \mathrm{m})$. At an amplitude of $8 \mathrm{~cm}$ and period of $2 \mathrm{~s}$, most of the Microcystis gathered at the surface after $1 \mathrm{~min}$. The surface aggregation decreased after 5 min disturbance, and the Microcystis were homogeneously distributed after $10 \mathrm{~min}$. The simulated values well agreed with the measured values, and exhibited the same behavior. Under less vigorous hydrodynamic conditions ( $A$ $=6 \mathrm{~cm}, T=2 \mathrm{~s} ; A=6 \mathrm{~cm}, T=3 \mathrm{~s}$ ), the simulated chlorophyll a concentration at the surface was higher than the measured one, and the simulated levels at lower depths agreed with the measured levels.

\section{Critical turbulent kinetic energy}

The critical turbulent kinetic energy $\left(\mathrm{T} K_{Z}\right)$ was proportional to colony diameter $(D)$ as equation 12 . The strong agreement between the measured and simulated values is clarified in Fig. 4.

$$
T K_{Z}=0.1555 D-6.7414\left(R^{2}=0.998, P<0.01\right)
$$

\section{DISCUSSION}

The 1-D wave simulator designed by Xiao et al. (2013) was used to simulate the water movement vertically only. It simplified the water movement of real lakes which varies temporally and spatially, and the simulation was reasonable. The vertical turbulence induced by the motor was strong at the deeper water column, which was consistent

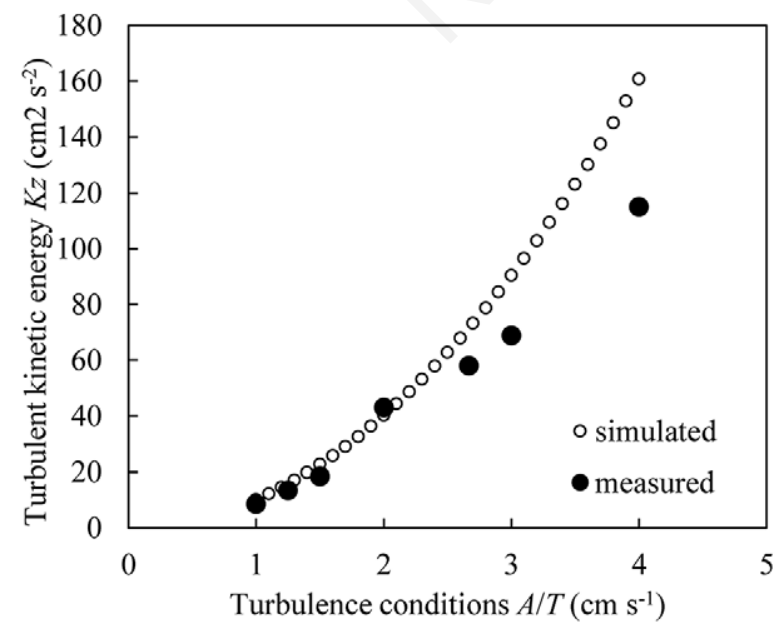

Fig. 2. Turbulent kinetic energy under different hydrodynamic conditions. with the investigations in Lake Taihu that, deeper layers had more intensive turbulence. Therefore, the effect of vertical water movement on the vertical distribution of Microcystis sp. could be well studied with the device and the experimental set up designed by Xiao et al. (2013). In the present study, model results have been compared with detailed measurements in three aspects (vertical flow velocity, the vertical distribution of Microcystis, and the critical turbulent kinetic energy of different-sized colonies). Simulated values agreed with measured values.

Water motion affects the vertical migration and distribution of Microcystis in lakes, rivers and reservoirs (Ha et al., 2000; Wallace et al., 2000; Medrano et al., 2013; Cui et al., 2016). Microcystis will migrate to the surface forming water blooms under weaker disturbance, and sink to deeper depths as water mixing become stronger. These observations consistent with our experimental data and model results.

On the other hand, hydrological conditions affect water blooms directly or indirectly by means of affecting the sizes of Microcystis colonies, which can alter the floating capacity of colonies. Large colonies may be destroyed to smaller colonies under oscillation mixing (Robarts and Zohary, 1984; O'Brien et al., 2004), and these smaller colonies can't overcome the drag force of turbulence and sink. Resulting in decrease of Microcystis biomass at the water surface. These may be a reasonable explanation for the discrepancy between measured and simulated Microcystis concentration at the surface under moderate mixing ( $A=6 \mathrm{~cm}, T=2 \mathrm{~s} ; A=6 \mathrm{~cm}, T=3 \mathrm{~s}$ ). Our simulation results showed that larger colonies $(>400 \mu \mathrm{m})$ can resist the disturbance and remain at the water surface under these two conditions. Some of these large colonies may break up into smaller colonies under sustained oscillation mixing in the experiments. While these smaller colonies would sink for that they can't resist turbulent mixing. Resulting in the decrease of Microcystis biomass at the water surface. But colonies break-up was ignored in our simulation, leading to the differences between simulated and measured Microcystis concentrations. The relationship between the measured and simulated Microcystis concentrations was showed in Fig. 5. The figure indicated that our model can accurately simulate the vertical distribution of Microcystis under different hydrodynamic conditions.

However, this kind of dispersion is small even for the highest turbulence intensities experienced by Microcystis in the field (O'Brien et al., 2004). Some studies discussed the influence of turbulence on the ecology of Microcystis (Reynolds, 1994; Wilkinson et al., 2016). Their results suggested that $M$. aeruginosa are powerful enough to tolerate intensive mixing for a few days ( $>96 \mathrm{~h}$ ) (Regel et al., 2004). In summary, it is reasonable to ignore the effect of turbulence on colony viability and size in simulation process, and simulated results are suitable for field. 
A: $8 \mathrm{~cm} ; \mathrm{T}: 2 \mathrm{~s}$

Chlorophyll a $\left(\mu \mathrm{g} \mathrm{L}^{-1}\right)$

$\begin{array}{lllllll}0 & 10 & 20 & 30 & 40 & 50 & 60\end{array}$

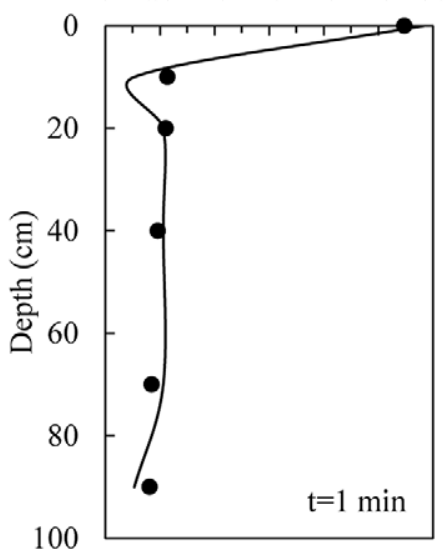

A: $6 \mathrm{~cm} ; \mathrm{T}: 2 \mathrm{~s}$

Chlorophyll a $\left(\mu \mathrm{g} \mathrm{L}^{-1}\right)$ $\begin{array}{llllll}0 & 20 & 40 & 60 & 80 & 100\end{array}$

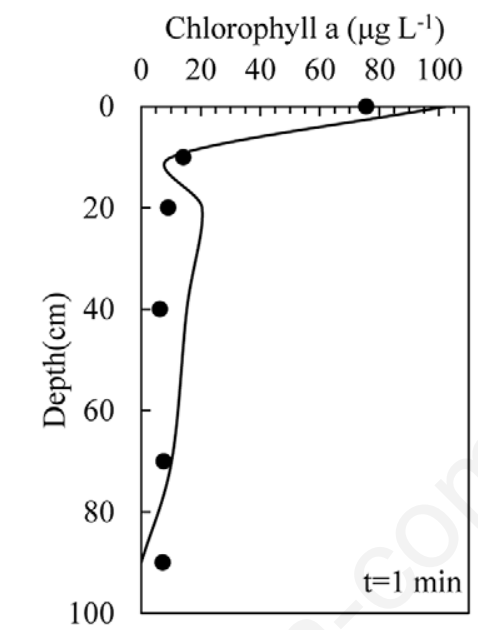

Chlorophyll a $\left(\mu \mathrm{g} \mathrm{L}^{-1}\right)$

$\begin{array}{lllllll}0 & 10 & 20 & 30 & 40 & 50 & 60\end{array}$

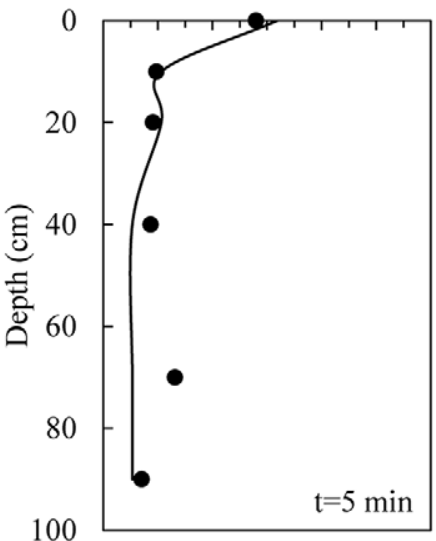

Chlorophyll a $\left(\mu \mathrm{g} \mathrm{L}^{-1}\right)$

$\begin{array}{lllllll}0 & 10 & 20 & 30 & 40 & 50 & 60\end{array}$

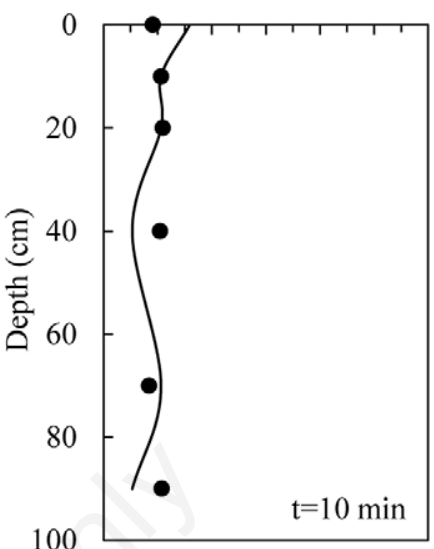

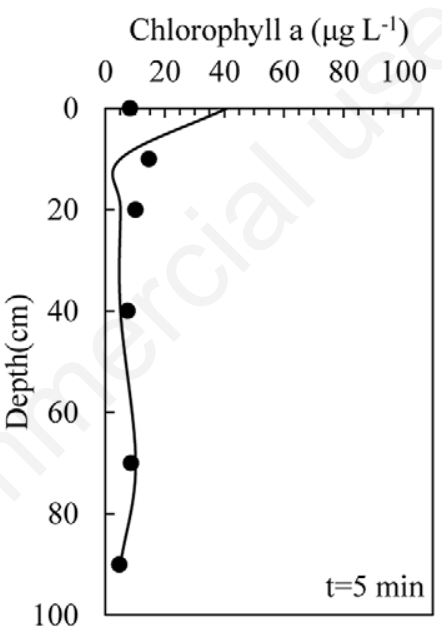

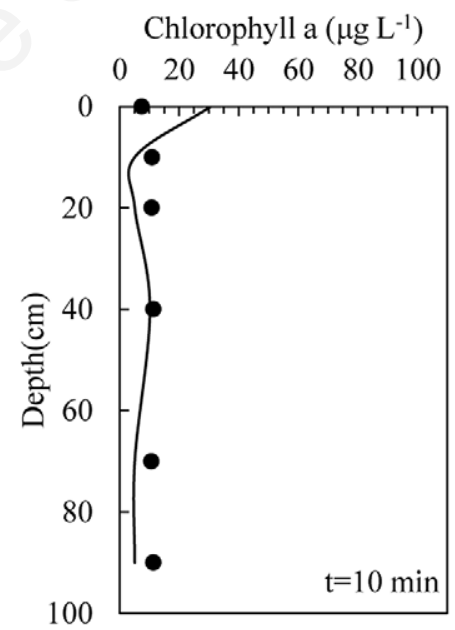

A: $6 \mathrm{~cm} ; \mathrm{T}: 3 \mathrm{~s}$
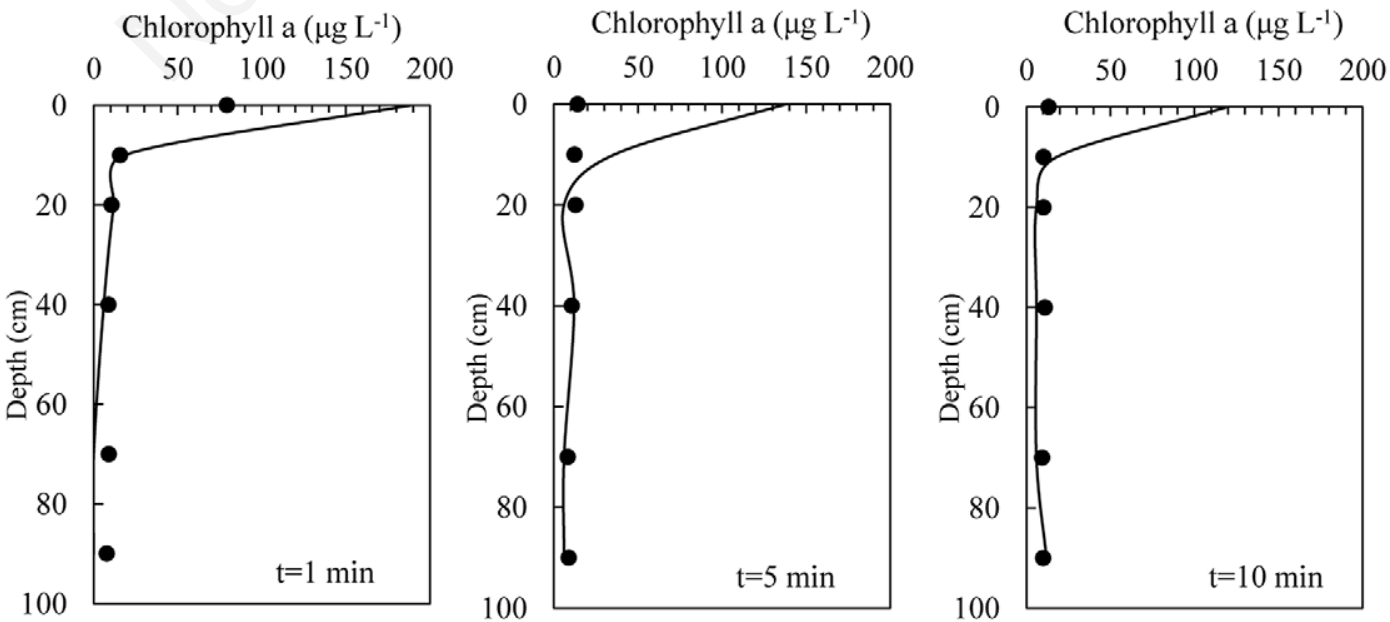

Fig. 3. The vertical distribution of Microcystis under different hydrodynamic conditions. The continuous lines are simulated results; the dots are measured results from Xiao et al. (2013). 
The phenomenon has been found that water blooms occurred under poor weather or nutrient conditions (Ozawa et al., 2005; Ma et al., 2015). The reason may be explained as the effect of water motion. It may not be suitable to predict the outbreaks of water bloom by simply relying on the nutrient, light or temperature. Establishing the relationship between water and Microcystis motion is necessary. While existing numerical models and studies reported consistent results. Namely, that Microcystis large colonies can resist turbulence and float to the surface whereas small colonies are easily mixed in the water column (Wallace et al., 2000, Medrano et al., 2013). But failed to quantify the relationship between disturbance resistance and colony diameter. In this study, our model computed the critical turbulent kinetic energies as eq. 12, above which the colonies will sink.

According to the long-term monitoring study of Meiliang and Gonghu Bays in Lake Taihu, a large shallow lake (Zhu et al., 2015), reported that during the water blooms season (October to December), Microcystis colonies are 300-400 $\mu \mathrm{m}$ wide in Lake Taihu (Zhu et al., 2016). The critical turbulent kinetic energy of $400 \mu \mathrm{m}$ colony is 55.5 $\mathrm{cm}^{2} \mathrm{~s}^{-2}$, it means that under this condition, most of the colonies will sink and the water blooms will disappear. In addition, the turbulent kinetic energy $\left(K_{Z}\right)$ is the following quadratic function of the wind speed $x$ in Lake Taihu:

$K_{Z}=3.12 x^{2}-0.56 x+22.65(\mathrm{Xiao}, 2014)$

(eq. 13)

Inserting the critical turbulent kinetic energy into this expression, the corresponding wind speed is determined

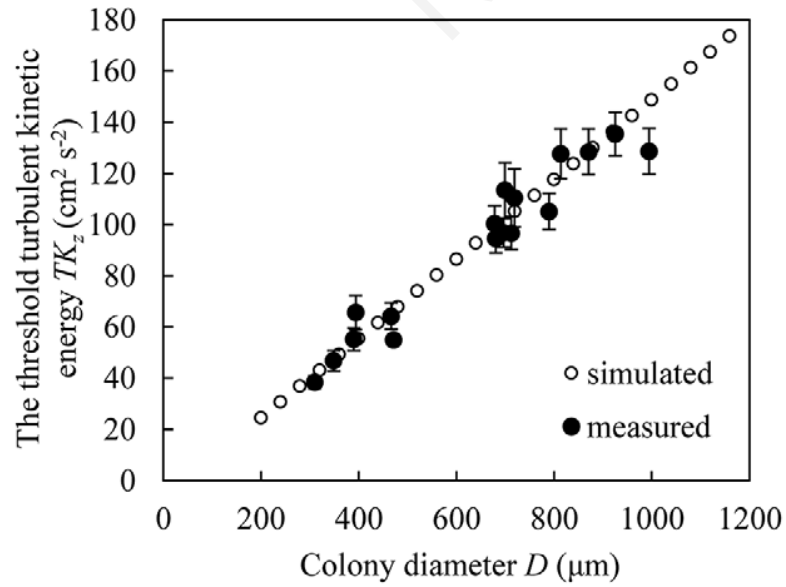

Fig. 4. The critical turbulent kinetic energy of different-sized Microcystis colonies. Error bars represent the standard deviation of measured values. as $3.3 \mathrm{~ms}^{-1}$, similar to the threshold wind speed $\left(3.0 \mathrm{~ms}^{-1}\right)$ at which the water blooms disappears in Lake Taihu (Zhu and Cai, 1997; Cao et al., 2006; Zhang et al., 2008). At a wind speed of $1 \mathrm{~m} \mathrm{~s}^{-1}$, the turbulent kinetic energy of water is $25.2 \mathrm{~cm}^{2} \mathrm{~s}^{-2}$, indicating that Microcystis colonies will sink if their diameters are below $200 \mu \mathrm{m}$. When the wind speed increases to $4.02 \mathrm{~m} \mathrm{~s}^{-1}$, the turbulent kinetic energy of water reaches $71.0 \mathrm{~cm}^{2} \mathrm{~s}^{-2}$, and colonies with diameters smaller than $500 \mu \mathrm{m}$ will leave the water surface. At a wind speed of $5.61 \mathrm{~ms}^{-1}$, the turbulent kinetic energy is $117.7 \mathrm{~cm}^{2} \mathrm{~s}^{-2}$, ensuring that even large colonies $(800 \mu \mathrm{m})$ are mixed throughout the water column. The critical turbulent kinetic energy is a useful parameter for predicting the occurrence and disappearance of water blooms and the depth at which Microcystis potentially occurs in different type of lakes.

Wind-waves frequently disturb phytoplankton and sediment in shallow lakes. Light, temperature and nutrients are homogeneous in the whole water column mainly affected by water disturbance (Nixdorf and Deneke, 1997). And colonies will be evenly mixed in the whole water column under intensive mixing conditions, assemble at the near surface in calm periods. However, in deep lakes, disturbance degree varies with depth under disturbance, thus different-sized colonies will gather at different depths (at which the turbulent kinetic energy of water no more than their critical energy). Microcystis will occur at this lower intensity mixing and deeper locations. Light, temperature, may not be favorable for Microcystis growth at deep layers, which will affect algal physiology of Microcystis. Thus affecting morphological and size of $\mathrm{Mi}$ -

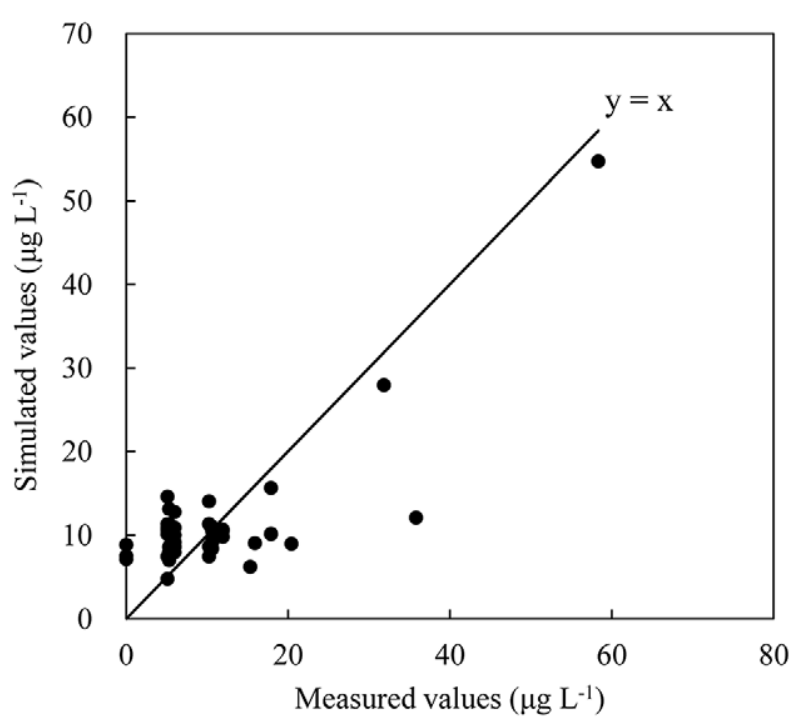

Fig. 5. The relationship between the measured and simulated Microcystis concentrations. 
crocystis colony. Shallow lakes may hold the potential to bear favorable conditions for the presence of Microcystis blooms, because of the homogeneous light, temperature, and turbulence mixing, as well as the frequently disturbance which can cause the release of nutrients from the sediment (Fan et al., 2004).

\section{CONCLUSIONS}

This paper introduced a vertical migration model of Microcystis colonies based on turbulence drag, revealing the mechanism by which turbulence and colony size affects the vertical migration of Microcystis. The critical turbulent kinetic energy $\left(\mathrm{T} K_{\mathrm{Z}}\right)$, above which the colony cannot resist the turbulence conditions and sinks, depends on the colony diameter. The critical turbulent kinetic energy is a useful parameter for predicting the occurrence and disappearance of water blooms in different type of lakes. The study is crucial for prediction and prevention of water blooms.

\section{ACKNOWLEDGMENTS}

The project was funded by the Program on Furtherance of Scientific Research of Japan, Fundament C (15K00630), the Lake Taihu water pollution control special funds (Tenth Phase) Scientific research topic (JSZCG2016-198), the Fundamental Research Funds for the Central Universities (2015B36214).

\section{REFERENCES}

Cao HS, Kong FX, Luo LC, Shi XL, Yang Z, Zhang XF, Tao Y, 2006. Effects of wind and wind-induced waves on vertical phytoplankton distribution and surface blooms of Microcystis aeruginosa in Lake Taihu. J. Freshwater Ecol. 21:231238.

Chen Y, Qian X, Zhang Y, 2009. Modelling turbulent dispersion of buoyancy regulating cyanobacteria in wind-driven currents, p. 1-4. In: Proc. 3rd Int. Conf. on IEEE Bioinformatics and Biomedical Engineering, 2009. ICBBE.

Chien YC, Wu SC, Chen WC, Chou CC, 2013. Model simulation of diurnal vertical migration patterns of different-sized colonies of Microcystis employing a particle trajectory approach. Environ. Eng. Sci. 30:179-186.

Cui YJ, Liu DF, Zhang J, Yang ZJ, Khu ST, Long LH, 2016. Diel migration of Microcystis during an algal bloom event in the Three Gorges Reservoir, China. Environ. Earth Sci. 75:1-9.

Ding Y, Qin B, Zhu G, Wu T, Wang Y, Luo L, 2012. Effects of typhoon Morakot on a large shallow lake ecosystem, Lake Taihu, China. Ecohydrology 5:798-807.

Dong CY, Luan WL, Zhou ST, Zhang Q, 2007. [Analysis and application of model for solid particle movement in Newton fluid].[Article in Chinese with English abstract]. J. China Univ. Petrol. (Edition of Natural Science) 31:56-63.
Fan CX, Zhang L, Qin BQ, Wang S, Hu W, Zhang C, 2004. Estimation on dynamic release of phosphorus from wind-induced suspended particulate matter in Lake Taihu. Sci. Chin. Ser. D. 47:710.719.

George D, Edwards R, 1976. The effect of wind on the distribution of chlorophyll a and crustacean plankton in a shallow eutrophic reservoir. J. Appl. Ecol. 13:667-690.

Ha K, Kim HW, Jeong KS, Joo GJ, 2000. Vertical distribution of Microcystis population in the regulated Nakdong River, Korea. Limnology 1:225-230.

Huisman J, Sommeijer B, 2002. Population dynamics of sinking phytoplankton in light-limited environments: simulation techniques and critical parameters. J. Sea. Res. 48:83-96.

Kromkamp JC, Mur LR, 1984. Buoyant density changes in the cyanobacterium Microcystis aeruginosa due to changes in the cellular carbohydrate content. FEMS Microbiol. Lett. 25:105-109.

Ma J, Qin B, Paerl HW, Brookes JD, Hall NS, Shi K, 2015. The persistence of cyanobacterial (Microcystis spp.) blooms throughout winter in Lake Taihu, China. Limnol. Oceanogr. 61:711-722.

Medrano EA, Uittenbogaard RE, Pires LMD, Van De Wiel BJH, Clercx HJH, 2013. Coupling hydrodynamics and buoyancy regulation in Microcystis aeruginosa for its vertical distribution in lakes. Ecol. Model. 248:41-56.

Nakamura T, Adachi Y, Suzuki M, 1993. Flotation and sedimentation of a single Microcystis floc collected from surface bloom. Water Res. 27:979-983.

Nixdorf B, Deneke R, 1997. Why 'very shallow' lakes are more successful opposing reduced nutrient loads. Hydrobiologia 342/343:269-284.

O'Brien KR, Meyer DL, Waite AM, Ivey GN, Hamilton DP, 2004. Disaggregation of Microcystis aeruginosa colonies under turbulent mixing: laboratory experiments in a gridstirred tank. Hydrobiologia 519:143-152.

Oliver RL, Walsby AE, 1984. Direct evidence for the role of light-mediated gas vesicle collapse in the buoyancy regulation of Anabaena flos-aquae (cyanobacteria). Limnol. Oceanogr. 29:879-886.

Ozawa K, Fujioka H, Muranaka M, 2005. Spatial distribution and temporal variation of Microcystis species composition and microcystin concentration in Lake Biwa. Environ. Toxicol. 20:270-276.

Rabouille S, Salençon M-J, Thébault J-M, 2005. Functional analysis of Microcystis vertical migration: a dynamic model as a prospecting tool: I-Processes analysis. Ecol. Model. 188:386-403.

Regel RH, Brookes JD, Ganf GG, Griffiths RW, 2004. The influence of experimentally generated turbulence on the Mash01 unicellular Microcystis aeruginosa strain. Hydrobiologia 517:107-120.

Reynolds CS, 1994. The role of fluid motion in the dynamics of phytoplankton in lakes and rivers. p. 141-187. In: P.S. Giller, A.G. Hildrew and D.G. Raffaelli (eds.), Aquatic ecology: scale, pattern and process. Blackwell Scientific Publications.

Reynolds CS, Oliver RL, Walsby AE, 1987. Cyanobacterial dominance: the role of buoyancy regulation in dynamic lake environments. New Zeal. J. Mar. Fresh. 21:379-390.

Reynolds CS, Jaworski G, Cmiech H, Leedale G, 1981. On the 
annual cycle of the blue-green alga Microcystis aeruginosa Kutz. emend. Elenkin. Philos. T. R. Soc. B. 293:419-477.

Robarts RD, Zohary T, 1984. Microcystis aeruginosa and underwater light attenuation in a hypertrophic lake (Hartbeespoort Dam, South Africa). J. Ecol. 72:1001-1017.

Serizawa H, Amemiya T, Rossberg AG, Itoh K, 2008. Computer simulations of seasonal outbreak and diurnal vertical migration of cyanobacteria. Limnology 9:185-194.

Van Rijn LC, 1984. Sediment transport, part I: bed load transport. J. Hydraul. Eng. 110:1431-1456.

Visser PM, Passarge J, Mur LR, 1997. Modelling vertical migration of the cyanobacterium Microcystis. Hydrobiologia 349:99-109.

Wallace BB, Bailey MC, Hamilton DP, 2000. Simulation of vertical position of buoyancy regulating Microcystis aeruginosa in a shallow eutrophic lake. Aquat. Sci. 62:320-333.

Walsby AE, 1994. Gas vesicles. Microbiol. Rev. 58:94-144.

White BR, Schulz JC, 1977. Magnus effect in saltation. J. Fluid Mech. 81:497-512.

Wilkinson A, Hondzo M, Guala M, 2016. Effect of small-scale turbulence on the growth and metabolism of Microcystis aeruginosa. Adv. Microbiol. 6:351.

Wu T, Qin B, Zhu G, Luo L, Ding Y, Bian G, 2013. Dynamics of cyanobacterial bloom formation during short-term hydrodynamic fluctuation in a large shallow, eutrophic, and windexposed Lake Taihu, China. Environ. Sci. Pollut. Res. 20:8546-8556.

Wu X, Kong F, 2009. Effects of light and wind speed on the vertical distribution of Microcystis aeruginosa colonies of dif- ferent sizes during a summer bloom. Int. Rev. Hydrobiol. 94:258-266.

Xiao M, 2014. [The influence of vertical turbulence on the vertical dispersion and accumulation of Microcystis colonies].[Article in Chinese with English Abstract]. Nanjing: Hohai University

Xiao M, Zhu W, Li M, Sun QQ, Nkrumah PN, Tan X, 2013. The influence of water oscillation on the vertical distribution of Microcystis colonies of different sizes. Fresen. Environ. Bull. 22:3511-3518.

Zhang M, Kong F, Wu X, Xing P, 2008. Different photochemical responses of phytoplankters from the large shallow Taihu Lake of subtropical China in relation to light and mixing. Hydrobiologia 603:267-278.

Zhu W, Li M, Dai X, Xiao M, 2015. Differences in vertical distribution of Microcystis morphospecies composition in a shallow hypertrophic lake (Lake Taihu, China). Environ. Earth Sci. 73(9): 5721-5730.

Zhu W, Li M, Luo Y, Dai X, Guo L, Xiao M, Huang J, Tan X, 2014. Vertical distribution of Microcystis colony size in Lake Taihu: Its role in algal blooms. J. Great Lakes Res. 40:949-955.

Zhu W, Zhou X, Chen H, Gao L, Xiao M, Li M, 2016. High nutrient concentration and temperature alleviated formation of large colonies of Microcystis: evidence from field investigations and laboratory experiments. Water Res. 101:167-175.

Zhu Y, Cai Q, 1997. [The dynamic research of the influence on wind field on the migration of algae in Taihu Lake].[Article in Chinese with English Abstract]. J. Lake Sci. 9:152-158. 